\section{Cardiac myxomas in an unusual location: A glimpse into their potential characteristics}

\author{
To the Editor,
}

In the clinical context, cardiac myxomas mostly emerge in middle-aged women and generally present with a variety of cardiovascular symptoms attributable to their constitutional, obstructive, and embolic manifestations (1,2). Traditionally, the left atrium (LA) has been the usual predilection site for these benign neoplasms $(2,3)$. However, atypical locations including left ventricular outflow tract (LVOT) have also been occasionally reported (3). In this context, the recently reported article by Kasmeridis et al. (1) has presented an atypical case of cardiac myxoma within the right ventricular outflow tract (RVOT) in a female patient. Therefore, we would like to make a few comments on this didactic case and the clinical implications of atypical myxoma locations.

First, cardiac myxomas in an unusual location might potentially suggest a familial background and warrant further investigation $(2,4)$. Importantly, familial cardiac myxomas, besides having a substantial proclivity for unusual cardiac locations, might potentially arise at multiple sites and have a significant risk for future recurrences $(2,4)$. Of note, these familial neoplasms emerge in isolation or in association with certain clinical entities including Carney's complex (mainly presenting with cutaneous tumors and endocrine abnormalities) $(2,4)$. This leads us to ponder about genetic analysis and family history of cardiac myxoma in this case. There is also a question regarding the presence of myxoma syndromes and their clinical manifestations (if any) in the patient.

Second, systemic inflammation has also been considered as a cardinal feature of cardiac myxomas and has been mostly associated with constitutional symptoms (fever, rash, etc.) and tumor embolism (2). More specifically, persistent increments in the levels of certain markers including interleukin- 6 were previously suggested to promote local recurrences following myxoma resection $(2,5)$. Interestingly, persistent systemic inflammation might also account for the evolution of distant myxomatous lesions mostly in the form of central nervous system (CNS) pathologies, including vascular aneurysms and solid parenchymal masses that might also arise as systemic recurrences even several years after the resection of primary cardiac tumor (2). Importantly, possibility of pulmonary recurrences manifesting as multiple parenchymal infiltrations should also be kept in mind in the setting of right-sided myxomas.

Taken together, persistent systemic inflammation might be associated with systemic and local recurrences of cardiac myxomas potentially indicating important clinical implications (mostly regarding prognosis and management strategies includ- ing close follow-up, anti-inflammatory strategies, etc.) (2). In this context, these implications seem to be more pronounced in the setting of familial cardiac myxomas (2) (and possibly in cardiac myxomas in an unusual location regardless of their genetic basis). Therefore, we would like to have information on the levels of inflammation markers in the pre and post-surgical settings along with the authors' future strategy (schedules of clinical visits, echocardiogram along with CNS, pulmonary imaging, etc.) for the timely detection of potential recurrences in this patient.

Finally, cardiac myxomas are also well known to elicit gradual valvular damage in certain settings mostly attributable to their direct impingement on valvular structures (6) during cardiac systole and/or diastole. As expected, valvular impingement during systolic phase is possibly more forceful due to the higher velocity, and therefore kinetic energy of the tumor mass at the time of its collision with valvular structures. In this context, valvular injury during cardiac systole is expected to be encountered predominantly in ventricular myxomas (7). Moreover, it is well known that any significant gradient across the ventricular outflow tracts [which could also be attributable to myxoma obstruction without direct impingement on the valvular structures (8)] generally creates a systolic turbulent jet flow that might eventually lead to structural degeneration in semilunar valves (manifesting as valvular regurgitation and/or stenosis in the longterm). Accordingly, we wonder about the magnitude of RVOT gradient along with the degrees of pulmonary valvular and right ventricular dysfunctions (if any) in the patient. Importantly, secondary valvular degeneration might be potentially overlooked in certain patients with myxoma, potentially warranting detailed examination of valvular functions before myxoma resection.

In summary, cardiac myxomas in an atypical location might potentially suggest a familial background generally indicating a detailed clinical evaluation along with genetic analysis $(2,4)$. Moreover, clinical relevance of systemic inflammation is possibly more pronounced in these myxomas (compared with classical myxomas involving the LA). Lastly, unusual myxoma locations including LVOT and RVOT $(1,2,7,8)$ might be particularly associated with the dysfunction of semilunar valves that need to be thoroughly evaluated, and where necessary, surgically managed during myxoma resection. However, these notions still need to be further tested in clinical trials.

\section{Kenan Yalta* (D), Uğur Özkan* (D), Tülin Yalta** (D), Ertan Yetkin1 ${ }^{\text {(D) }}$ \\ Departments of *Cardiology, and **Pathology, Faculty of Medicine, Trakya University; Edirne-Turkey \\ 1Department of Cardiology, Derindere Hospital; İstanbul-Turkey}

\section{References}

1. Kasmeridis C, Katerinis E, Vogiatzis I. Asymptomatic, echocardiography-detected, right ventricular outflow tract sited myxoma. Anatol J Cardiol 2021; 25: E32. [Crossref] 
2. Yalta K, Ozturk C, Yalta T, Yetkin E. Systemic Inflammation in the Setting of Cardiac Myxomas: an Overview of Clinical and Practical Considerations. Korean Circ J 2021; 51: 784-6. [Crossref]

3. Yalta K, Turgut 00, Yilmaz A, Yilmaz MB, Ozyol A, Karadas F, et al. Left ventricular outflow tract myxoma accompanied by dextrocardia with situs inversus: a case report. Int J Cardiovasc Imaging 2007; 23: 329-32. [Crossref]

4. Mahilmaran A, Seshadri M, Nayar PG, Sudarsana G, Abraham KA. Familial cardiac myxoma: Carney's complex. Tex Heart Inst J 2003; 30: 80-2.

5. Mendoza CE, Rosado MF, Pacheco P. Interleukin-6 production and recurrent cardiac myxoma. J Thorac Cardiovasc Surg 2001; 121: 395-6. [Crossref]

6. Rose MR, Fox AC, Glassman E, Reed GE. Left atrial myxoma and aortic regurgitation. Case report. J Thorac Cardiovasc Surg 1974; 68: 797-801. [Crossref]

7. Panwar S, Banerjee A, Mohan JC, Tomar AS. Aortic leaflet injury caused by left ventricular myxoma: a hitherto unreported association. Indian Heart J 2000; 52: 328-30.

8. Kim DH, Yi JE, In HJ, Jeong M, Kim MS, Lee JS, et al. Asymptomatic myxoma originating from the right ventricular outflow tract. $J$ Cardiovasc Ultrasound 2013; 21: 186-8. [Crossref]

Address for Correspondence: Dr. Kenan Yalta,

Trakya Üniversitesi Tıp Fakültesi, Kardiyoloji Anabilim Dalı, Edirne-Türkiye Phone: +90 5056579856

E-mail: kyalta@gmail.com, akenanyalta@trakya.edu.tr (C) Copyright 2021 by Turkish Society of Cardiology -

Available online at www.anatoljcardiol.com

DOI:10.5152/AnatolJCardiol.2021.797

\section{Author`s Reply}

\section{To the Editor,}

We would like to thank the authors of the letter to the editor, "Cardiac myxomas at an unusual location: A glimpse into their potential characteristics" for the interest in our published case in your journal titled, "An asymptomatic, echocardiographydetected, right ventricular outflow tract (RVOT) sited myxoma" (1) and his knowledgeable comments. We take this opportunity to respond to the issues raised in the letter and to discuss further in detail, in our view, another major impact related to the case.

With up to $85 \%$ of all myxomas originating in the left atrium, the most common attachment site is the left atrial septum (2-4). In the context of Carney's complex, a syndrome of cardiac myxomas inherited as an autosomal dominant pattern, associated with cutaneous pigmentation and fibromyxoid tumors of the skin, myxomas may be detected at other sites as well, involving right-sided locations $(5,6)$. With an incidence of approximately $20 \%$, the right atrium is the second most common location after the left atrium, followed by the ventricles. Right ventricle myxomas are detected rarely, with an occurrence rate of $4 \%$ to $5 \%$, whereas the right ventricle outflow tract (RVOT) as an attachment site of the myxoma is even rarer (2-4).
General symptoms of weakness, fever, loss of weight, anemia, and elevated inflammatory markers are related to secretory properties of the myxoma and especially to interleukin- 6 and other mediators $(7,8)$.

Our patient was generally asymptomatic, and the clinical presentation was unremarkable. As the commonly measured nonspecific inflammatory markers in clinical practice (C-reactive protein, erythrocyte sedimentation, and procalcitonin) were within normal limits, a persistent generalized inflammatory state could be excluded. Pulmonary angiography performed on the patient's admission failed to diagnose a pulmonary embolism, and pulmonary parenchymal infiltrations were not detected. A body CT scan was also performed in the pre-excision period at the hospital where the patient was referred to for the surgery, which was negative for solid parenchymal masses.

This data could probably lead to the conclusion that the stable (in terms of embolism) myxoma that was observed in our patient with, therefore, a lower risk of distant myxomatous lesions is directly connected to the lack of tumor's secretory properties attributable mainly to interleukin-6 (9). As the embolic phenomena are associated with papillary myxomas, which are smaller with multiple villi, a non-papillary subtype myxoma would be expected in our patient's case (5).

A diagnosis of Carney's complex was not considered possible as no skin lesions were detected, neither was endocrine pathology suspected on the basis of clinical presentation and later blood analysis. In addition, no familial history of myxomas was reported or any other symptomatology to a close relative that could be attributed to a possible diagnosis of cardiac myxoma. Of note, the patient had no children at that time, and her parents had passed away of natural causes.

Patients with right-sided myxomas potentially may present with important right heart-related clinical symptoms. The RVOT obstruction may lead to right heart failure with central and/or peripheral edema and myxoma-related emboli to acute pulmonary embolism and pulmonary hypertension $(3,6,10)$.

Our patient did not present with any heart failure symptoms related to blood flow obstruction. Transthoracic echocardiography study (Fig. 1) did not reveal RVOT gradient or raised right
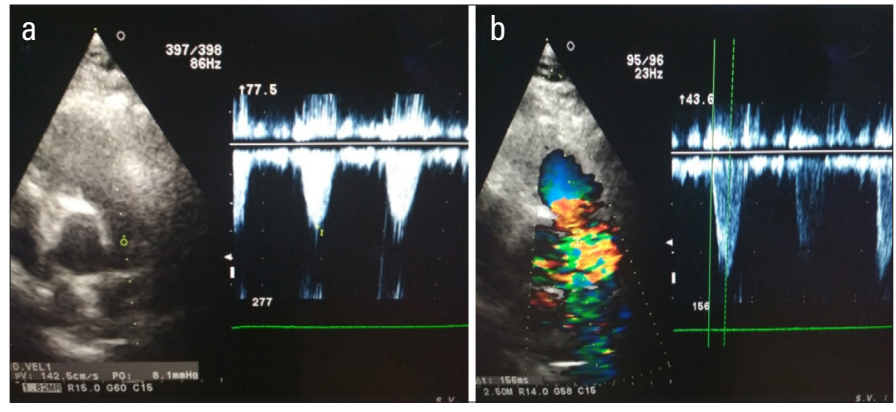

Figure 1. Transthoracic echocardiographic views - parasternal short axis views revealing: (a) a low continuous wave max systolic gradient along the right ventricular outflow tract and pulmonary artery, (b) a pulse wave (PW) normal value of acceleration time of pulmonary ejection (AccT >150 ms) without midsystolic "notch", highlighting a non-raised right ventricular pressure overload 
ventricle afterload. Magnetic resonance imaging (MRI) later revealed left and right ventricles with normal dimensions and normal systolic function, without wall motion abnormalities or wall aneurysms. Myxoma appeared in RVOT approximately 2.0$2.5 \mathrm{~cm}$ below the pulmonary valve, which seemed to be adhered by a stalk to the anterior free wall, without valvular impingement during the systolic phase. As a result, no valvular injury during cardiac systole was expected.

Finally, after surgical excision, our patient was scheduled for a long-term follow-up for the potential diagnosis of tumor recurrence. This consisted of a follow-up examination, typical blood samples including nonspecific inflammatory markers, chest $x$-ray, and serial echocardiographic studies, at least yearly, to be followed up for the next 5 to 10 years (11). As the patient was low risk in terms of persistent inflammatory state in the pre-excision period, a central nervous system and pulmonary imaging strategy are not considered an option at present. Till date, surgical excision is considered curative with excellent and uncomplicated results, and our patient is recovering.

In conclusion, this is an interesting case because of the unusual site of the myxoma, the general absence of symptoms in the patient, and at the same time the absence of embolic episodes, which is equivalent to the absence of pulmonary embolism. This case confirms the need for an individualized approach in cardiac myxoma as well as the value of transthoracic and transesophageal echocardiography in detection, differential diagnosis, and monitoring of random heart tumors in terms of routine cardiac imaging. MRI is the imaging method of choice that essentially sets the diagnosis before the biopsy will confirm it. After diagnosis, surgery should be performed urgently to prevent tumor-related complications. Follow-up should be performed regularly, including echocardiography, for the timely diagnosis of potential recurrences.

\section{Charalambos Kasmeridis (D), Efthimios Katerinis (D, loannis Vogiatzis (D)}

Department of Cardiology, General Hospital of Veroia; VeroiaGreece

\section{References}

1. Kasmeridis C, Katerinis E, Vogiatzis I. Asymptomatic, echocardiography-detected, right ventricular outflow tract sited myxoma. Anatol J Cardiol 2021; 25: E32 [Crossref]

2. Bjessmo S, Ivert T. Cardiac myxoma: 40 years' experience in 63 patients. Ann Thorac Surg 1997; 63: 697-700. [Crossref]

3. Mittle S, Makaryus AN, Boutis L, Hartman A, Rosman D, Kort S. Right-sided Myxomas. J Am Soc Echocardiogr 2005; 18: 695. [Crossref]

4. Goldberg HP, Glenn F, Dotter CT, Steinberg I. Myxoma of the left atrium; diagnosis made during life with operative and post-mortem findings. Circulation 1952; 6: 762-7. [Crossref]

5. Vidaillet HJ Jr, Seward JB, Fyke FE 3rd, Su WP, Tajik AJ. "Syndrome myxoma": a subset of patients with cardiac myxoma associated with pigmented skin lesions and peripheral and endocrine neoplasms. Br Heart J 1987; 57: 247-55. [Crossref]

6. Farah MG. Familial cardiac myxoma. A study of relatives of patients with myxoma. Chest 1994; 105: 65-8. [Crossref]

7. Panidis IP, Kotler MN, Mintz GS, Ross J. Clinical and echocardiographic features of right atrial masses. Am Heart J 1984; 107: 74558. [Crossref]

8. Wold LE, Lie JT. Cardiac myxomas: a clinicopathologic profile. Am J Pathol 1980; 101: 219-40.

9. Saji T, Yanagawa E, Matsuura H, Yamamoto S, Ishikita T, Matsuo N, et al. Increased serum interleukin-6 in cardiac myxoma. Am Heart J 1991; 122: 579-80. [Crossref]

10. Sugeng L, Lang RM. Atypical cardiac myxomas. Echocardiography 2004; 21: 43-7. [Crossref]

11. Cianciulli TF, Cozzarin A, Soumoulou JB, Saccheri MC, Méndez RJ, Beck MA, et al. Twenty Years of Clinical Experience with Cardiac Myxomas: Diagnosis, Treatment, and Follow Up. J Cardiovasc Imaging 2019; 27: 37-47. [Crossref]

Address for Correspondence: Ioannis Vogiatzis MD,

Department of Cardiology, General Hospital of Veroia; Veroia-Greece Phone: 00302331351253 / 00306944276230

E-mail: ivogia@hotmail.gr

(C) Copyright 2021 by Turkish Society of Cardiology -

Available online at www.anatoljcardiol.com 